\title{
El arte en la mala conciencia epistemológica: Contexto para un cruce peligroso
}

\author{
Andrés Mombrú* \\ amombru56@yahoo.com.ar
}

\section{Resumen:}

Ciencia y arte han tenido a lo largo de la historia diferentes tipos de consideración y se los ha vinculado de diversas maneras. La modernidad, rememorando la tradición platónica, los separa en esferas diferentes, en un contexto social y cultural en el que el arte, no debe ser, como para el ateniense, condenado al ostracismo, pero si lo deja pendiendo de una tensión entre una producción que indica lo inefable y una mercancía que sólo cumple con el propósito de gustar o entretener -como cualquier otra mercancíacareciendo de todo atributo de racionalidad. La ciencia ha sido concebida como el ámbito del intelecto, de la razón, de la reflexión; y el arte como una actividad vinculada a la emoción, a la sensibilidad y a la inspiración. Sin embargo esos arquetipos estereotipados, que han sido funcionales a ciertas lógicas del dominio, esconden otras dimensiones y otros vínculos que pueden ser más afines a proyectos emancipadores, capaces de integrar lo que se quiere mantener por separado con el fin de legitimar estructuras de poder. Se reflexiona aquí sobre los motivos de algunas de las controversias que esta tensión ha generado, que alternativas se ponen en juego en la realización del mundo social y cultural y que consecuencias pueden tener para el destino de nuestra cultura.

Palabras clave: ciencia, estética, epistemología, cultura, educación

\section{Abstract:}

Science and art have had throughout history different types of consideration, and they have been linked in various ways. Modernity, recalling the platonic tradition, separates them in different spheres, in a social and cultural context in which art doesn't need to be ostracized, as the athenian philosopher claimed, but it is hanging by a tension between a production

\footnotetext{
* Andrés Mombrú es Licenciado en Filosofía, Especialista y Magister en Metodología de la Investigación Científica y Doctor en Filosofía. Se desempeña en la Universidad de Buenos Aires como Asociado de la materia Metodología de las Ciencias Sociales y en la Universidad Nacional de Lanús, como Coordinador académico de la Especialización y la Maestría en Metodología de la Investigación Científica. Es titular en varias materias de grado y posgrado, investigador, escritor y editor de libros y revistas científicas.
} 
that indicates the ineffable and a commodity that only serves the purpose of pleasing or entertaining -as any other commodity-, lacking any attribute of rationality. Science has been conceived as the realm of intellect, reason, reflection; and art as an activity linked to emotion, sensitivity and inspiration. However, these stereotypical archetypes, that have been functional for certain logics of domination, hide other dimensions and other links that may be more related to emancipatory projects capable of integrating what was intended to be kept separate in order to legitimize power structures. Here we reflect on the reasons for some of the controversies that this tension has generated, on what alternatives come into play in the realization of the social and cultural world, and on the consequences that these alternatives may have for the destiny of our culture.

Keywords: Science, art, epistemology, culture, education

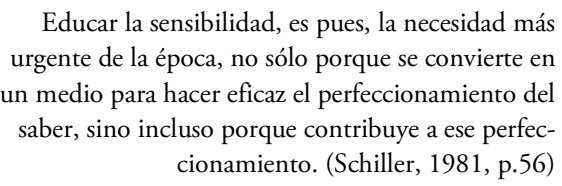

Ciencia y arte son términos que, en nuestras realidades culturales contemporáneas, refieren a dos actividades humanas que suelen ser concebidas como pertenecientes a campos diferentes que apenas sí se tocan circunstancialmente. Sin embargo, esta separación que los distingue tan tajantemente, que identifica el ámbito de la ciencia con el conocimiento racional, la actividad intelectual, el conocimiento verdadero o "encaminado hacia la verdad", la producción de saberes, la reflexión ordenada, sistematizada por métodos racionales; y al arte, como el ámbito de la intuición, de la sensibilidad, de la expresión de emociones, de sentimientos, de aspectos irracionales que se expresan impulsivamente como una forma de "locura" o "posesión divina", fue pergeńada bastante tiempo antes de que la ciencia moderna, asociando matemática, deducción y experimento se diera un nuevo estatus gnoseológico y ontológico y se desentendiera del arte. Ya Platón en varias de sus obras, Hipias, Fedro, Ión, Teeteto y principalmente en La República establece no solamente la tajante diferencia entre la tan venerada "episteme", y la despreciable "doxa", sino también entre éstas y la menos valiosa, pero no despreciable del todo tekné de los artesanos y la condenable tekné de los artístas. En La República, Platón equipara las destrezas y atributos del poeta, del escultor, del músico, con las del auriga, del criador de caballos, o del panadero, pero poniendo a los últimos como conocedores, por lo menos, de una técnica necesaria, en tanto a los primeros, como posesos irracionales, recomendando su expulsión de la República por corruptores del alma racional. Para Platón todas las artes son imitativas; degradaciones ontológicas del ser, que tiene consecuencias morales sobre el alma humana y por ello todas deben ser desterradas de la Polis, la cual debe convertirse en el ámbito que favorezca el ascenso del alma al mundo uránico. Según señala, entre las "buenas leyes" deben estar aquellas que impiden que los artistas convivan 
con el resto de los ciudadanos, porque sus prácticas, "acaban con la razón" y "corrompen a los ciudadanos más prudentes". (Platón, 2008, 605b, c; 607b)

La elocuencia de Platón no deja lugar a dudas, la ciencia pertenece al ámbito de lo que enaltece, pues se realiza bajo la esfera del intelecto, en tanto que el arte degrada y corrompe por tener como recurso a las facultades sensibles; camino de ignorancia y engaño, fuente de irracionalidad que surge de lo inferior, las emociones y los sentimientos. Resulta paradójico, pero hay una enorme pasión irracional en contra del arte entre éstos racionalistas. En no pocas repúblicas reales, se ha perseguido, y se persigue aún, al arte y a los artistas sobre la base de ese antagonismo. Nunca las ideas y las prácticas científicas fueron calificadas de degeneradas, tal como se ha considerado a manifestaciones estéticas. Por otra parte, no es posible generalizar esos conceptos como expresión de toda la filosofía, sólo de algunas producciones, pero de aquellas que han prevalecido en la construcción de los valores más extendidos y representativos de Occidente.

En la Edad Media, la filosofía no desaparece, pero ella se diluye en la teología. En este período la idea de ciencia es asociada a iluminación, la fe tutela a la razón y pone sus atributos al servicio de la religión. No otra cosa sucede con el arte, el cual, abandona los motivos paganos de celebración de la vida y de la naturaleza, con todo lo bueno y lo trágico que pudieran tener, y se convierte en el primer multimedia de la historia, fabricando buenos cristianos, a partir de campesinos analfabetos, mediante los recursos de la pintura, la escultura, los vitro, la arquitectura, el canto. Podríamos decir, parafraseando a Althusser, que el aparato ideológico de la religión había alcanzado su más alto grado de desarrollo y sofisticación constituyéndose en un antecedente del Estado Moderno y de los mass-media contemporáneos por medio del arte. Sólo más tarde el Renacimiento vuelve a otorgar la autonomía y el liderazgo a la razón y a la ciencia, pero reconsiderando también el lugar del arte. Este último retorna al centro de la escena ya no inspirado por el espíritu dionisíaco o báquico, que había alentado la idea de la vida como goce, -racional o sensible-, sino con expectativa similares a las de la ciencia moderna, -heredera en parte de la alquimia y la magia- revelar los arcanos, aunque por otros caminos muy diferentes. Las búsquedas en el arte transitarán abrumadas de ambigüedad; inspiradas por un lado por el ansia de celebración y el sentido de finitud e inmanencia y por otro por el ansia de eternidad, que busca el sentido en la trascendencia. Las artes y las ciencias son renacidas con un propósito integrador con la vida, pero al mismo tiempo son portadoras de las dicotomías del mundo griego y de las contradicciones con que avasalla la modernidad. Muy pronto serán nuevamente separadas, alejadas y encerradas en nichos que les impidan "contaminarse" mutuamente.

El Renacimiento fue un período en el cual supieron converger las capacidades del artista y del científico. El paradigma de todos ellos es Leonardo Da Vinci. No nos referimos a sus obras como científico y como artista, sino a lo que de ciencia hay en su arte y a lo que de arte hay en su ciencia, y al propósito común que impulsa a ambas. Impulso que se encuentra imbuido de las contradictorias aspiraciones de la nueva clase emergente, la burguesía, con sus proyectos emancipadores que claman por la libertad y sus mezquindades económicas que aspiran sólo a la ganancia, al control, y que justifican la guerra como modo de obtención de rique- 
za, -aunque las disfrace con el atuendo de sus otras aspiraciones-. La sonrisa de la Gioconda, los aparatos voladores, y las armas de guerra, de Leonardo, no revelan simplemente su genio, sino la ambigüedad de una sensibilidad estética, y de un conocimiento científico, en el cual se vislumbra la emergencia de una razón, y de una estética, que por un lado están esperanzadas por la emancipación de la humanidad y por el otro no pueden ceder frente a sus afanes de poder. En este período las ideas y las prácticas quieren integrar el arte, la ciencia, la filosofía, la técnica, la moral, la fe; pero resultan atravesadas por la ambigüedad, de un proyecto que comienza a naufragar entre las expectativas de emancipación de los tutelajes de la religión, que venía cargando, y el surgimiento de nuevas formas de sujeción que nacen del nuevo orden económico y político, traicionado de este modo aquel principio de integración, y produciendo lo que Max Weber (1983) llamará la ruptura de las esferas del arte, la ciencia y la moralidad. Esta fragmentación es consecuente con un acelerado proceso de secularización, de desarrollo económico y productivo que necesita a toda costa generar nuevas y lucrativas formas de producción. Las nuevas condiciones económicas y sociales son profundamente estimulantes para la creatividad científica y artística, todavía unidas por la herencia de la Edad Media, pero bajo un nuevo cielo humanista. A partir de este momento los vínculos entre estas esferas, no sólo con la de la moralidad, como nos plantea Weber, sino también con las esferas del comercio, de la técnica, de la producción y de las finanzas, junto con las de los nuevos ordenes políticos y el surgimiento de los Estados Nacionales modernos, conducirá a la fragmentación sistemática, a la atomización compulsiva, y a la esquizofrenia creativa.

En ese corto período del Renacimiento, el arte, la ciencia y la religión, ya no se encuentran unificados, pero tampoco separados del todo. Ellos conviven aún y por poco tiempo bajo el dominio hegemónico del Estado moderno que organiza la sociedad y sus producciones de acuerdo a una nueva lógica. Hasta que la guillotina corte de cuajo ese vínculo. Es en este nuevo escenario que la supervivencia de estas disciplinas tiene que adaptarse a nuevos esquemas de poder. Y frente a ese poder, que tiene la particularidad de convertir todo en mercancía, hay dos formas en que los artistas se presentan: revelándose o adaptándose. La revelación conduce a la exclusión, a la expulsión de los nuevos ámbitos que son consagrados de acuerdo a los esquemas de ordenamiento de la producción capitalista. El arte abandona los templos, en los cuales la pertenencia era colectiva, y bajo formatos mercantiles ingresa a los nuevos ámbitos de las galerías y colecciones privadas. De cualquier manera, nada se desperdicia, incluso los disidentes, que pueden ser maltratados, perseguidos, recluidos, encarcelados o asesinados, entregan su producción, la que se puede comercializar bajo el formato de artistas malditos, científicos locos, o marginales varios.

Los que se adaptan en cambio pueden hacerlo desde diferentes lugares. Como sirvientes y justificadores de las políticas de los que les dan un espacio, recursos, incluso poder, convirtiéndose de ese modo en cómplices del poder mismo, -una vuelta de tuerca del antiguo mecenazgo, pero ahora principalmente bajo la tutela del Estado-ya en su condición de "[...] enanos más o menos ingeniosos que pueden ser alquilados para cualquier uso”, como señalara Bertolt Brecht en su obra Galileo Galilei, refiriéndose a los científicos. Su arte pierde entonces su contenido reflexi- 
vo y crítico, y se convierte en propaganda política, o en la estética -no precisamente de una nueva moralidad-. También están los que adoptan una posición distinta, esto es, los que forman parte de los organismos e instituciones en las cuales se reproduce un disciplinamiento que legitima las prácticas, afiata las ideologías y se ejerce el poder; pero desde una postura aparentemente crítica, que cuestiona esos mismos funcionamientos institucionales; que reflexiona y propone otras prácticas, otras relaciones y otras lógicas, pero que, sin embargo, no se encuentra completamente desembarazada del todo de la ideología que critica y, teñida en parte por esa lógica, vive en la esquizofrenia de la ambigüedad entre la crítica y la reproducción.

La suerte de los disidentes puede ser de lo más variada, pero la eficacia de sus ideas y acciones no depende solo de ellos, sino de un entramado mucho más complejo que se relaciona con la lucha dentro de los distintos campos, debatiéndose entre dos estrategias antagónicas, la de la voluntad de poder ser con los otros o la de la voluntad de poder ser mediante el dominio.

Queremos mostrar aquí que no se trata de un conflicto maniqueo, en el cual el arte es una fuerza explosiva que quiere resguardar la libertad y la sensibilidad humana y poner a recaudo las emociones y los sentimientos, frente a una ciencia que progresivamente irá abandonando sus expectativas emancipativas y se irá convirtiendo en un saber técnico instrumental, puesto al servicio del dominio y del sometimiento, como sostuviera Horkheimer en Crítica de la razón instrumental (1973). La razón crítica, que los frankfurtianos reivindican frente a aquella razón instrumental, no proviene exclusivamente del campo de la filosofía, ella se encuentra presente también en las filas de la ciencia y del arte. Del mismo modo, como en la ciencia hay razón instrumental y también razón crítica y por supuesto, sensibilidad instrumental y crítica, de igual manera en el arte hay un arte emancipador y un arte servilatravesado por similares dicotomías. De este modo, lo cuantitivo cobra otra dimensión, ya que el tema no es en qué o en quienes se alojan estas lógicas, puesto que lo hacen en todo, sino cuanto de una y de otra son conformadoras de formas de estar en el mundo y de constituirse las producciones y las relaciones sociales.

¿Qué es lo que la voluntad de poder ser con los otros pretende? Juego, participación. Jugar en el campo, compartir todos los elementos que lo conforman para la obtención de un deleite que construye el mundo humano, en definitiva, "goce". Pero un goce que sabe que el objeto de su deseo no se alcanza mediante el auto hedonismo, sino en la dialéctica del mutuo reconocimiento. Esta lógica se manifiesta en los valores del reconocimiento recíproco, en la disputa fraterna, en la solidaridad, en la ayuda mutua y en la certeza de que no se puede gozar sin producir goce.

¿Qué es lo que la voluntad de dominio pretende? Plantear el campo como una arena en la que se mata o se muere, se es conquistador o conquistado, "winner" o "looser", en donde lo que se dirime es la apropiación de lo común y el poder para fijar arbitrariamente las reglas.

Utilizamos el término juego para expresar las intenciones lúdicas que motivan dentro de un campo las luchas por la voluntad de poder ser con los otros, y orientan 
la actividad creadora y productora de sentido y de prácticas en un contexto de libertad y mutuo reconocimiento.

Utilizamos el término voluntad de poder como dominio para expresar las intenciones de imponer formas únicas de producción de sentido y prácticas en un contexto autoritario.

Entendemos que la lucha por instalar una cosmovisión que se expanda y se convierta en praxis científica, estética y social es absolutamente legítima. Desde esta perspectiva se plantea un escenario de debate constante, tanto con otras cosmovisiones, cuanto con sus propios presupuestos. El intento de este tipo de expansión requiere de la capacidad de convivir con otros paradigmas, pero bajo la premisa del reconocimiento recíproco. De modo que, siguiendo esta definición, entendemos el juego como el intento por realizar la voluntad de poder ser con los otros en un clima de consentimiento, esto es, de respeto y reconocimiento reciproco dentro de tratos amigables, amorosos, philiae. Cuando, en cambio, lo que se produce es una lucha por imponerse, sólo hay lugar para el pensamiento único, para las prácticas autoritarias y, a la postre, destructivas de toda creatividad. Suponemos los debates científicos, estéticos y epistemológicos como atravesados por todos los matices de estas lógicas contradictorias.

Cuando la lógica de la voluntad de dominio prevalece, se convierte en justificadora de la dominación mediante la fuerza, la violencia, y por supuesto, la fuerza y la violencia de las palabras y los actos. En el plano social esto se produce cuando el Estado ejerce el dominio político y la ciencia y el arte se ponen al servicio de éste y/o del mercado y no como expresión o manifestación libre de la comunidad y de los individuos, es allí cuando la ciencia se convierte en tecno-ciencia y el arte en propaganda, o modos enajenantes de distracción. La idea de un arte valorativamente neutro, abocado sólo a la búsqueda de la belleza, es tan absurda como la idea de una ciencia que se considera valorativamente neutra, porque su finalidad es sólo el conocimiento. Las "miserias del arte" no radican exclusivamente en la vacuidad y en la frivolidad, -las que pueden ser incluso venturosas- sino en sus compromisos con las lógicas de la dominación.

¿Por qué emergen manifestaciones enajenantes, incluso en el arte? Porque esas producciones no pierden de vista el goce, bajo formas enajenadas es cierto, pero goce al fin. La búsqueda de felicidad y placer por parte de las mayorías, no siempre encuentra el "gusto" en lo que le conmueve o hace reflexionar, sino, la más de las veces en lo que "entretiene" y/o aleja las preocupaciones. Por otro lado, el arte que pretende, en su ser crítico, expresar toda la tragedia de la vida y las significaciones más profundas, olvidando la alegría y el goce, conlleva, las más de las veces, la impronta de un tipo de sufrimiento, -el que ignora la dialéctica goce sufrimiento- que pierde de vista otras dimensiones del goce, al que considera "pasatista", perdiendo de vista una dimensión superior del goce estético, el cual implica la máxima energía de los atributos racionales y emotivos, incluso para esas mayorías a las cuales desprecia y a las que suele considerar como ineptas y que aleja cada vez más de sí. Las mayorías incultas -si pudieran los hombres vivir al margen de tipo alguno de cultura y llamadas así por un concepto excluyente, para el cual cultura es sólo la propia- pueden vivir adormecidas por los cantos de sirena de la industria cultural, pero poco favor le hacen quienes intentan "cultivarlas" con producciones 
que son ajenas a su sensibilidad y racionalidad. En el arte y en la ciencia, en los que prevalece la lógica de dominio, se potencia el egoísmo y la competencia, en oposición a la solidaridad y la ayuda mutua y al reconocimiento de lo diferente, aunque tenga la apariencia de lo elevado, de lo crítico o de lo "humano".

Es de considerar que en ciertos ámbitos los motivos de ambiciones personales, exitismo, poder, dominio habrían de ser prescindibles; sin embargo, estas situaciones se encuentran presentes incluso en instituciones que se suponen presididas por los más altos principios. En Mi credo Humanista, Einstein señala que ese espíritu competitivo predomina incluso en escuelas y universidades, destruyendo todos los sentimientos de cooperación y fraternidad. Para Einstein esto es grave, porque impide el "amoral" trabajo fecundo y compartido. No es que Einstein se desdoble en científico y filósofo para realizar esta afirmación, ella emerge de su condición de pensador integral. Es interesante su claro diagnóstico, referido a situaciones dentro de ámbitos que se suponen propios de la civilización y no de la barbarie y que, sin embargo, producen situaciones tan miserables, aún en ámbitos insospechados. Pero la lógica del dominio se introduce en todos los rincones y se cuela en todas las grietas. A pesar de la lucidez de Einstein en muchos aspectos éticos lo alcanza el espíritu del cientificismo y no se da cuenta de que nada puede emerger del "amoral trabajo fecundo y concienzudo", porque las moralidades y los valores atraviesan las prácticas sociales, incluidas las científicas y las estéticas. En este sentido, no hay práctica que se produzca por fuera de algún tipo de valoración. No hay, ni ciencia, ni arte, valorativamente neutros; la cuestión es saber cuáles son los valores que se encuentran animando las prácticas y cuáles pueden ser las consecuencias que pueden producir. Pensar estas cuestiones nos dispone dentro del campo filosófico, como es de suyo propio, con la lógica, la ética, la estética, la gnoseología y la metafísica. En este sentido, la epistemología ha de ser concebida al mismo tiempo como filosofía y como ciencia social, ya que no estudia entidades abstractas, ni naturales, sino producciones humanas, las qué, quizás todas ellas, no sean más que otras formas diferentes de arte.

Insistimos en que la epistemología es una disciplina, pero también es una actitud, un modo de ser en el universo científico social, sin el cual, no hay transformación social, cultural o científica. Cuando, por ejemplo, un biólogo que se ha formado muy rigurosamente en su disciplina, deja sus instrumentos conceptuales y materiales de lado y se pone a reflexionar sobre la posibilidad de entender los problemas que se le plantean a su investigación, los procedimientos que sigue; de considerar cambios en el modo de concebir su objeto y sus métodos, no está haciendo biología, está haciendo epistemología de la biología. Sin esa actitud, sin esa reflexión crítica de sus propios presupuestos la biología difícilmente hubiera llegado a lograr algo. Ese proceso de distanciamiento reflexivo del científico -si es científico y no un ciego técnico- muchas veces lo tiene incorporado, no repara en ello, pero es lo que impulsa su investigación. La idea del arte como acto crítico en sí mismo, carga al arte de una aureola de sabiduría que no posee per se, sino que surge de la reflexividad crítica del artista, la que muchas veces el mismo artista no puede diferenciar de su producción estética.

Si seguimos pensando el arte al modo platónico, como la actividad de posesos, entonces sólo queda para el artista la inspiración de las musas. El artista lleva ade- 
lante su obra imbuido de inspiración, pero también de conocimiento, no sólo de las técnicas que le permiten expresar su arte, sino del mundo y de aquello que es su motivo de creación. En él, tanto como en el científico, se encuentra la capacidad de articular lo inarticulado, de reunir lo caótico en torno a una significación. El artista pinta, esculpe, compone, escribe, pero también siente y reflexiona sobre su actividad, incluso más que el científico, o mejor dicho, que los científicos empobrecidos y disminuidos en sus capacidades creativas a causa del sometimiento a la lógica dominante. Pero también la inspiración, la creación, se encuentran presentes en la investigación científica tanto como en la estética. Se nos podrá decir que la diferencia es que mientras la inspiración conduce en el científico al descubrimiento, esto es, a revelar lo que ya estaba produciéndose, -la verdad como adecuatio- es en el arte que se da la creación. Pero estas concepciones no se encuentran exentas de un fuerte determinismo histórico. La ciencia experimental moderna tuvo que desplazar a la religión para reinar hegemónica en un amplio campo de saberes, pero también el arte tuvo que repaganizarse para liberarse de la tutela del arte religioso. Sin embargo, no lo hizo del todo. La ciencia, -por lo menos el tipo de ciencias defendido por la ortodoxia, que todavía prima en la mayoría de los ámbitos de producción de conocimiento- cargó en su nacimiento con la cruz de tener que ofrecer verdades tan omniabarcativas, tan absolutas, tan verdaderas como la religión, pero no ya fundadas en la fe, sino en la evidencia empírica o en la certeza deductiva de los razonamientos válidos. El arte tampoco se ha terminado de liberar de la sombra de la religión, el artista sigue anhelando ser a imagen y semejanza de su creador, es decir, un creador. Aunque a partir de la modernidad ya no está para alabar a Dios y ganar la trascendencia de le otorga la divinidad, sino que busca la trascendencia a través de su propia obra. El yo cartesiano no solamente es expresión de una nueva subjetividad en el campo de la ciencia y la filosofía, sino también del arte. El sujeto racional y el sujeto estético inauguran al unísono el yo moderno. Sujeto alucinado por "el sueño dogmático" de la razón y de la sensibilidad moderna. A pesar de ello una ruptura más profun$\mathrm{da}$, una libertad más plena, sigue pendiente en las búsquedas del arte, una búsqueda que termine definitivamente de emancipar al goce de las exigencias de la trascendencia sobrenatural. Este drama, vivido a fondo, fue la contradicción que desgarró a Nietzsche. Como señala Marcuse (1969)en Eros y Civilización, si bien Nietzsche expone la gigantesca falacia sobre las que se han construido la filosofía y la moral de Occidente, todavía hay en su filosofía demasiados elementos del terrible pasado. La intención de recuperar el espíritu dionisíaco no logra el último momento de la metamorfosis. El superhombre no llega a alcanzar el estado del niño, -la capacidad del goce sin culpa- porque la máxima moral de la voluntad de poder quiere que las conductas merezcan ser fijadas para la eternidad. Tras la muerte de Dios perdura la prisión del eterno retorno. En ese contexto la voluntad no llega a ser la auténtica expresión del goce y la libertad, porque ella misma es todavía una prisionera. Entendemos que esos elementos del terrible pasado, que se preservan en la filosofía de Nietzsche, tienen que ver con el ansia de trascendencia y la búsqueda de eternidad. El arte no logra ser el ámbito de la liberación precisamente porque se quiere eterno. Sólo la gratuidad de lo inmanente le permitiría alcanzar para sí su única y plena realización. Sólo un sentido de trascendencia que 
repare en que trascender no es durar para la eternidad, sino salir de sí a la búsqueda de un encuentro con otro, partiendo de que ese otro es portador de una irreductible libertad, y que junto con él, y en el mundo, podrá alcanzar una auténtica emancipación. Como señalara Alejo Carpentier en El reino de este mundo:

En el Reino de los Cielos no hay grandeza que conquistar, puesto que allá todo es jerarquía establecida, incógnita despejada, existir sin término, imposibilidad de sacrificio, reposo y deleite. Por ello, agobiado de penas y de tareas, hermoso dentro de su miseria, capaz de amar en medio de las plagas, el hombre sólo puede hallar su grandeza, su máxima medida en el Reino de este Mundo. (Carpentier, 1973, p.81)

Agregaríamos, sin Dios, sin trascendencia transfinita, sin eterno retorno, en su inmanencia existencial y en el encuentro de su trascendencia humana, que necesita bien poco para realizarse. Pero esto remite a un problema de vieja data. Epicuro nos dice: "Grita la carne: no tener hambre, no tener sed, no tener frío, quien tenga estas cosas o espere tenerlas, también con Zeus puede rivalizar en felicidad." (Epicuro, 1973, p.147) A esto Aristóteles respondió que si la felicidad consistiera en comer arvejas podríamos llamar felices a los bueyes. De algún modo la tensión que se presenta en estos conceptos nos acompaña hasta el presente. En El ocaso de los idolos Nietzsche señala: "Para vivir solo hace falta ser un animal o un dios, dice Aristóteles. Falta una tercera condición: hay que ser ambas cosas, es decir, un filósofo [...]" (Nietzsche, 1988, p.3) Parafraseándolo podríamos decir: para vivir no hace falta ni ser un dios, ni un animal, ni un filósofo, -como la combinación de ambos- hace falta ser un niño. Tener la capacidad de gozar sin culpa, abrirse a la curiosidad y a la aventura, crear por pura gratuidad, sin ningún otro fin que el mismo goce que produce, tan evanescente e inmanente como la propia vida. El desencanto de Nietzsche le lleva a pesar que el hombre es algo a ser superado, quizás la cuestión sea que en realidad todavía es un animal, que sueña con ser un Dios, y que alucina como un filósofo y no ha conseguido todavía la revelación para sí de lo que significa ser un hombre. Nietzsche lo indica en el tercer momento de la metamorfosis. Mientras tanto nos debatimos como camellos o como leones, tensados entre el sometimiento y la ira. La ciencia, el arte y la filosofía todavía guardan el interrogante sobre ¿qué es ser un hombre? Un interrogante corrompido por aquellos que quieren -como Aristóteles- que los muchos sean animales, mientras se reservan para sí, mediante la opresión de esos, los atributos de lo divino.

Cuando a comienzos de la modernidad quedó atrás la redención divina como esperanza sincera, emergieron otras alternativas emancipatorias. Para Kant fue la salida del hombre de su autoculpable minoría de edad mediante la razón ilustrada, para Hegel fue la elevación de la autoconciencia, para Marx fue el trabajo. Para otros, de las más diversas layas, la esperanza de emancipación se encontró en el arte. Sin embargo, este no resultó ni inocente ni inmaculado, y permanentemente se ha movido en las ambigüedades de la celebración y la necrofilia. Estremece la belleza necrófila de la poesía de Filippo Marinetti, uno de los más importantes referentes de las vanguardias estéticas de principios del siglo XX, máximo representante del futurismo, en cuyo Manifiesto Futurista, expone, con una sensual 
belleza, que seduce y causa horror al mismo tiempo, su culto a la guerra, a la destrucción, al avasallamiento de los débiles, su desprecio por la mujer y su apología de la muerte. No se trata de meras metáforas, sino del aliento necrófilo y homicida de una poesía que terminará conformando la estética del fascismo. La destrucción de museos, la quema de libros, el avasallamiento de los "otros" hasta el exterminio mediante las más horribles formas de crueldad, deja de ser una imagen poética, una metáfora de la renovación y se convierte en práctica criminal.

No se trata por lo tanto de la mera reconciliación de las esferas, ni su integración superadora, sino de plantear en el campo, que tipo de ciencia, de arte y de moral se espera reconciliar, concibiéndolas en su realidad escindida, pero también en su potencialidad integradora. Por ello es que nos parece relevante advertir que subyacen lógicas y estrategias diferentes, y que además esto se complica porque las mismas posturas suelen estar teńidas de su contrario. Con el planteamiento de las categorías voluntad de poder ser con los otros o voluntad como conquista y dominio no se quiere presentar una postura maniquea, sino reconocer en las producciones discursivas los enfrentamientos y los vínculos que se producen son en extremo complejos. Ejemplificaremos esas luchas más adelante con casos, que para parafrasear a Deleuze, nos ponen enfrente de verdaderos personajes, detrás de los cuales se esconden inciertas personas.

En los ámbitos sociales y culturales, más allá de las recusaciones filosóficas, arte, ciencia y moral constituían una esfera única en la cual sus contenidos se articulaban y complementaban. Tanto la idea de ciudadano en la polis griega, como la de creyente en el mundo medioeval cristiano, apuntaban a la conformación de un sujeto cuya virtud consistía en la búsqueda de lo bueno, lo bello, lo sabio y lo justo y los recursos de la moral, la política, la ciencia y el arte se complementaban en esa tarea. Esto no hacía a los hombres mejores, ni a las sociedades más justas y dignas, pero hacía a los sujetos menos esquizofrénicos. Sus vidas privadas, sus valores, los mandatos sociales, las múltiples manifestaciones de la vida cultural integraban a los sujetos. Los poemas cantan al Dios y revelan el lugar que cada uno ocupa en el cosmos o la creación.

La ciencia, el arte y la religión han tenido una búsqueda común, un mismo fin con diferentes propósitos y significados. La naturaleza, el trasmundo, la imaginación, son los ámbitos de la búsqueda de la verdad. Una verdad ontológica, una verdad lógica, una verdad moral, una verdad estética. Ese propósito era el mismo previo al Renacimiento, pero este período trae cambios significativos.

Según Max Weber (1983) la esferas del arte, la ciencia y la moral se autonomizan en la modernidad. Ellas, que constituían una unidad inescindida, se separan en esferas autónomas. De este suceso se desprenden una serie de consecuencias que darán algunas de las características primordiales de la modernidad. Si bien Weber alaba las cualidades de la ciencia como una forma de saber progresivo, responsable y que, en el caso del arte, no es dado hablar de progreso en ese sentido; su discurso está teñido de la idea de una diferencia entre arte y ciencia que mantiene, a pesar de que parece diferir con la tradición, una continuidad con ella. Para Weber ciencia y arte son esencialmente diferentes. Descalifica la idea de que la ciencia constituya verdades a secas e incluso sin caducidad en el tiempo, en cambio asigna estos atributos al arte. Entendemos que ese tipo de distinción tam- 
bién es parte de la mistificación del arte y la búsqueda de que más allá de la inmanencia hay algo que perdura o indica lo atemporal. Estas intenciones son también compartidas por la ciencia, el arte y la religión.

La labor científica, en efecto, está inmersa en la corriente del progreso, en tanto que en el terreno del arte no cabe hablar, por el contrario, del progreso en el mismo sentido. Es absolutamente refutable decir que la obra de arte de una época en la que se encuentran a su disposición nuevos medios técnicos y conocimientos mucho más profundos acerca de las leyes de la perspectiva sea, simplemente por esto, muy superior a otra obra ejecutada en tiempos en los cuales no existían dichos medios ni se tenía noción de tales leyes, siempre y cuando, claro está, que esta obra haya sido realizada materialmente con exactitud y según la forma debida, mejor dicho, que para ella se hubiera elegido y tratado su finalidad de acuerdo con las posibilidades artísticas, sin contar con esos medios y esas leyes. Una obra de arte, a la cual se considere en verdad "acabada", no podrá jamás ser superada ni envejecerá nunca. Un individuo podrá estimar de distinto modo el valor que esta obra representa para él, en lo personal; sin embargo, de estar una obra verdaderamente "lograda" en sentido artístico, jamás podrá nadie decir de ella que alguien la supere con otra, así esté esta otra igualmente "lograda". (Weber, 1983, p.10)

Respecto de este juicio de Weber, Habermas reflexiona que la separación de las esferas de la ciencia, la moralidad y el arte, que previo a la modernidad se encontraban unificadas por la religión, al separarse cada una bajo su "esfera" de incumbencia, permitieron la legitimación de los discursos científicos y estéticos para ser tratados como: "[...] problemas de conocimiento, de justicia y moral o de gusto”. (Habermas, 1988) Este registro ezquizofrénico que también distribuyó áreas de poder y de mercado, fue la base que garantizó la progresiva reproducción de la fragmentariedad de las actividades, de los saberes y de las prácticas dentro de nuevas lógicas de enajenación. Lo que destacó en hombres del Renacimiento como Leonardo, Miguel Ángel o incluso Galileo, fue su enorme capacidad y creatividad, pero sus múltiples actividades en diferentes campos eran algo bastante frecuente en ese período. Sólo en los esquemas miserables de la modernidad tardía, en la que cada sujeto está sujetado por una única actividad, -su fuente de enajenación- es que, otras prácticas resultan extrañas, y resulta extraño hoy que alguien pueda revelar habilidades intelectuales y manuales, técnicas y estéticas, emotivas y racionales. Pensamos que por suerte nada dura para siempre y que los proyectos de emancipación y liberación también han de librar su lucha contra estos encorsetamientos.

Entendemos que las formas del arte, al igual que las de la ciencia, tienen plazo de caducidad. Que lo que hace que una obra humana sea considerada como maestra es la significatividad que adquiere para una determinada cultura. Es la sintonía entre la obra y su capacidad de conmover y transformar a la sociedad y a los espiritus, la que la convierte en obra de arte, pero sólo, y no es para nada poco, en la 
medida en que esa sintonía es significativa, es decir, dadora de significado, generadora de sentido y agente de transformación. Lo que una obra de arte significa para una época difiere de lo que pudiera significar para otra. No todo lo que es arte conmueve a todos, en todo momento y por los mismos motivos. La capacidad resignificante de una obra es parte de su potencial. El que una época pueda resignificar, o no, a una obra, no invalida, ni a la obra, ni a la época: simplemente nos habla de transformaciones en la sintonía entre obra y sensibilidad.

Por otra parte, hay muchas cosas que pueden conmover, esto es, sacudir el espíritu transformándolo a partir de una experiencia determinada. La experiencia estética es sólo una de ellas. También la ciencia puede conmover en este sentido, pero el modo en que se produce esa conmoción tiene la apariencia de ser muy diferente al modo en que conmueve el arte. Definimos aquí espíritu como los aspectos humanos que tienen la particularidad y la capacidad de transformarse a sí mismos y transformar su mundo, fuera de los determinismos biológicos o naturales, aunque indisolublemente asociados a ellos. En la tradición de Occidente el espíritu fue identificado con las capacidades racionales superiores, y/o con el alma, y/o con una sensibilidad emocional. En este contexto entendemos por espíritu toda actitud, disposición, aptitud que genera el mundo humano. Se ha sostenido que mientras que la ciencia llega al espíritu a través del arduo trabajo de la razón, como el escarpado sendero que lleva del fondo de la caverna a su luminoso exterior -tal cual menta la alegoría de Platón- el arte lo hace por un camino más directo; impacta de lleno sobre el espectador de un modo instantáneo. Sería largo respaldar bibliográficamente esta idea que atraviesa la experiencia cultural de Occidente. Sin embargo, diferimos de esa idea y entendemos que la experiencia estética sólo tiene la apariencia de ser instantánea, que en realidad no es inmediata, sino vertiginosa. Mientras la digestión de los conceptos de la ciencia nos lleva por un largo camino reflexivo, por complejas cadenas deductivas, con importantes componentes lógicos, y también emocionales; el arte, en cambio, recorre otro camino, diferente, aunque no menos complejo que el del concepto, pero que se resuelve en cuestión de segundos o minutos, generando la ilusión de la instantaneidad y por lo tanto, se presenta como una experiencia extraordinaria, por mucho tiempo tenida por sobrenatural o mágica. Entendemos que en realidad convergen vertiginosamente ideas, experiencias, sensaciones, conceptos, que conforman una matriz que acoge de inmediato la experiencia estética y la significa de un solo golpe, creando la sensación maravillosa de ponernos frente a la revelación o el misterio. Pero, en su interior no se encuentra la iluminación instantánea, sino un proceso altamente complejo, intrincado, atravesado por procesos similares a los que impulsan el pensamiento científico, pero manifestándose "a la velocidad de la luz". La ciencia siempre ha envidiado esa capacidad del arte y las mentes científicas, tenidas por las más brillantes, son aquellas que han mostrado una extraordinaria capacidad de sintetizar vertiginosamente respuestas sencillas a cúmulos de problemas complejos. La diferencia se encuentra en el modo del fluir, por lo menos para los que carecemos del talento para la ciencia y para el arte. A los que contamos con los dedos nos parece prodigioso aquel que es capaz de realizar operaciones de cálculo diferencial en segundos y en el aire. En todo caso, con la debida paciencia, las operaciones matemáticas se podrán llegar a realizar, y en esto no se 
diferencian los grandes cerebros calculadores de la ciencia de los llamados savant. La neurociencia parece dar testimonio que entre el genio estético, el genio científico y el idiota hay más similitudes que diferencias, esto es bueno para no endiosar a los que consideramos genios, no subestimar a los que consideramos idiotas y en todo caso no sentirnos infelices por considerarnos "normales". De algún modo, se trata de algo que ellos poseen y que a nosotros "normales", se nos escapa, algo que nos fascina a los mortales mediocres y que es patrimonio de los talentosos, ello es, poder expresar lo extraordinario.

Ahora bien, se podría decir que lo extraordinario que nos traen la ciencia y el arte es de naturaleza muy diferente. Mientras que lo extraordinario cientifico radica en la revelación de los arcanos de la naturaleza, lo extraordinario del arte nos conduce a la imaginación, a la ficción y al misterio. Mientras que en la ciencia lo extraordinario se encuentra en el descubrimiento de la condición de extraordinario de lo objetivo, lo extraordinario del arte es fantasía subjetiva que podría revelar o indicar el misterio. Algunos definen esto como ilusión. Pero el ilusionismo que es un arte, sólo se puede llevar a la práctica mediante concienzudos conocimientos de la ciencia. A la base de la ciencia se encuentra el a priori de inteligibilidad, que nos dice que no sabemos a ciencia cierta si el mundo existe, pero vamos a poner esa duda entre paréntesis y suponer que sí. No lo decimos en un sentido metafórico, ¿̇no son construcciones auténticamente ilusionistas los conceptos de hiperuniversos, que son posibles sólo a partir de las matemáticas más sofisticadas? Son construcciones fantasiosas que pueden o no tener su correlato realista, universos imaginados que ni la más febril alucinación de los poetas o pintores podría llegar a elucubrar, y no importa si son confirmadas por nuevas evidencias empíricas o refutadas por las mismas, no es su función decir la verdad del mundo, sino la de poder pensar y construir la realidad humana.

¿Qué impulsa al hombre en esas búsquedas? En las selvas, del mismo modo que los animales, o en las ciudades supertecnológicas del presente, el hombre tiene la capacidad de sobrevivir. No es su amenazada existencia física como especie la que genera la angustia, sino el temor por la conciencia de su fragilidad y su finitud, y por sobre todo ello, por la idea de la falta de un sentido y de una significación esperanzadora. Este es uno de los elementos que como común denominador hermanan a la ciencia al arte y a la religión; la necesidad de encontrar a toda costa un sentido significador. Pero, el hecho es que muchos de los significados que han producido han sido ambiguamente tan opresivos y agobiantes como liberadores y reconfortantes. Ambos aspectos integran nuestra condición humana.

Cuando el arte y la ciencia se quieren edificantes y ejemplares, suelen perder su capacidad significadora, ocultando y enajenado las resonancias de nuestra interioridad. Dicho de otro modo, engañosa es la ciencia y el arte que quieren enseñarnos que es la vida y como debemos vivirla. En todo caso, lo mejor que nos pueden aportar es su compañía, en un trayecto que nos permita revelarnos a nosotros mismos, en nuestra gozosa y dolorosa situación de seres inmanentes. No siempre el arte nos conmociona gratamente, ni está allí para "complacernos"; no siempre levanta nuestro espíritu; muchas veces puede ser tan oprimente y depresivo, como las evidencias de la ciencia, y no por ello menos revelador, extraordinario, significador y excitante. 
¿Tiene hoy algún sentido hablar de la integración, o quizás unificación del arte, de la ciencia y de la moral? En primer lugar es necesario dar cuenta de las características fundamentales que han adquirido estas dimensiones en la modernidad, para luego pensar en qué medida es posible una "reunificación" de estas esferas. Pero hay otras preguntas que puede conducirnos a respondernos acerca de qué cosa impide esa reunificación. ¿Hay alguien a quién le interese esa reunificación? ¿Hay alguien que se beneficie de la escisión de las esferas? Al respecto Habermas nos responde del siguiente modo:

Los filósofos del iluminismo, como Condorcet por ejemplo, todavía tenían la extravagante esperanza que las artes y las ciencias iban a promover no sólo el control de las fuerzas naturales sino también la comprensión del mundo y del individuo, el progreso moral, la justicia de las instituciones y la felicidad de los hombres. Nuestro siglo ha conmovido este optimismo. La diferenciación de la ciencia, la moral y el arte ha desembocado en la autonomía de segmentos manipulados por especialistas y escindidos de la hermenéutica de la comunicación diaria. Esta escisión está en la base de los intentos, que se le oponen, para rechazar la cultura de la especialización. (Habermas, 1998, p. 5)

El poder enajenante de la lógica de la voluntad de poder como dominio, no obra de un modo omnímodo, que se impone a todo como un dios tiránico y autoritario, sino de un modo difuminado, infiltrando los intersticios más recónditos del entramado social. Filósofos, intelectuales, periodistas, comentaristas, comunicadores de diferentes layas, y toda la aceitada máquina de la industria cultural, sostienen no sólo la separación de las esferas, sino la fragmentación al infinito de espacios, áreas, terrenos, campos, sobre los que se pueda ejercer un gran o pequeño poder, el que reporta grandes o pequeñas ganancias a sus "propietarios". Este no es sólo un problema estético o epistemológico, es también un problema de mercado, cuyo resultado es la fragmentación y la esquizofrenia.

Hay algo que, si bien puede estar sujeto a controversias en cuanto a su estatus epistemológico, es, como fenómeno cultural, un hecho: existen corrientes epistemológicas profundamente cruzadas y gestadas por contenidos estéticos que las constituyen. El problema que aquí subyace no es simplemente si hay elementos del orden de la estética atravesando ciertos discursos epistemológicos consustanciados con la lingüística, la hermenéutica; la idea del discurso epistemológico, como relato que lo emparenta con la literatura, la poesía o incluso la música y la plástica, ni tampoco si en la producción misma del conocimiento científico se encuentran elementos constitutivos del orden de lo estético, sino: en qué medida arte y ciencia puedan unificarse en otro modo de creación y conocimiento como modos de construcción que sean impulsados por otras lógicas que no sean las de dominio y una forma de hedonismo que trascienda el onanismo.

Es necesario que establezcamos que no nos planteamos encontrar giros discursivos estéticos en el más o menos parco, aburrido e insulso discurso científico. No intentamos tampoco descubrir en el discurso de científicos y epistemólogos las marcas de una perspectiva estética que dulcifique sus argumentos, que los haga más 
amables a las almas sensibles, sino que pretendemos identificar en ellas un común denominador que las trasciende y que tiene el potencial de reconstituirlas. En alguna medida esto se podría albergar bajo el complejo y polémico concepto de creación, que suele ser ajeno a los afanes de la ciencia.

Es un lugar común reservar el término creación para los más altos productos de la actividad estética, en tanto que se piensa que lo que la ciencia hace es descubrir y que lo que la tecnología hace es inventar. Así han sido distribuidas y asignadas estas capacidades: el arte crea, la ciencia descubre y la tecnología inventa, se ha garantizado de ese modo la sistematización de las áreas del mercado. Pero nada puede ser descubierto si no hay un sostén complejo de índole histórico, social y cultural, del cual emergen las teorías científicas como verdaderas creaciones y como verdaderos inventos y nada puede ser creado sin el "conocimiento" que descubra para el artista las fuentes cognitivas, técnicas, tematizables, significativas de su creación. Sin esto, como se ha dicho, sólo podemos suponer que el artista es un infeliz poseído por las musas, un pobre tipo en cuya práctica no hay nada de racionalidad ni de inspiración que le pertenezca; sino, como el pobre Ion, un ser reducido a reproducir simulacros degradados y degradantes, como lo presenta la dialéctica platónica.

En la lógica de dominio, en lo que se convierten el científico, el artista y el técnico es en fabricantes de mercancías. En este contexto la prostitución y mercantilización de la belleza es llevada adelante por la tecnología como una argucia de la tecno-ciencia. La belleza de los objetos cotidianos, la excelsitud en el diseño, han perdido ese potencial que en el primitivo condujo al arte, y se ha convertido en un recurso de la industria por renovar la estética de la mercancía, una bella forma para la vacuidad.

Entendemos que vivimos un tiempo en que estas esferas se encuentran divorciadas y manipuladas por los especialistas y el mercado, pero que también subyacen en ellas conceptos, prácticas, modos de producción y de creación capaces de rescatarlos de la enajenación.

¿Cómo distinguir una obra de arte y un producto de la industria cultural? A la hora de discriminar estas cuestiones los filósofos de la escuela crítica de Frankfurt nos han dado una clave, lo que en realidad es arte no puede ser reducido a mercancía, su carácter ha de ser necesariamente negativo de la lógica que administra las ciencias y las artes, asignándoles modos diferentes de la verdad, de una verdad del arte que no vaya en contra de las verdades de la ciencia. Dicho de otro modo, así como en la ciencia, en el arte también encontramos ideología y formas de reproducción de lo dado.

Con el progreso del iluminismo sólo las obras de arte verdaderas han podido sustraerse a la simple imitación de lo que ya existe. La antítesis corriente entre arte y ciencia, que las separa entre sí como "sectores culturales", para convertir a ambas, como tales, en administrables, las transfigura al fin, justamente por su cualidad de opuestas, en virtud de sus mismas tendencias, a la una en la otra. La ciencia, en su interpretación neopositivista, se convierte en esteticismo, sistema de signos absolutos, carente de toda intención que lo trascienda: se con- 
vierte en suma en ese "juego" respecto al cual hace ya tiempo que los matemáticos han afirmado con orgullo que resume su actividad. Pero el arte de la reproducción integral se ha lanzado, hasta en sus técnicas, a la ciencia positivista. Dicho arte se convierte una vez más en mundo, en duplicación ideológica, en reproducción dócil. La separación de signo e imagen es inevitable. Pero se ha hipostasiado con ingenua complacencia; cada uno de los dos principios aislados tiende a la distribución de la verdad. (Adorno, 1970, p.18)

Lo que aquí nos interesa no es denunciar el sustrato ideológico del arte y su participación en los modos de la voluntad de ser con los otros y de la voluntad como dominio, sino, teniendo en cuenta que es falaz la distinción de roles que se asigna y que las tres disciplinas: arte, ciencia y tecnología, crean, descubren e inventan a pesar del disciplinamiento disciplinar por escindirlas y de los intentos de los especialistas por administrarlas según sus conveniencias, que, tanto en la ciencia como en el arte, se albergan recursos emancipadores y unificadores que surgen de sus tensiones internas, atravesadas por el conjunto de las contradicciones sociales. Y lo hacen a pesar de toda postura en contrario, lo hacen aunque no se den cuenta que lo hacen y prediquen la escisión. Al respecto Deleuze señala:

A decir verdad, las ciencias, las artes, las filosofías son igualmente creadoras, aunque corresponda únicamente a la filosofía la creación de conceptos en sentido estricto. Los conceptos no nos están esperando hechos y acabados, como cuerpos celestes. No hay firmamento para los conceptos. Hay que inventarlos, fabricarlos o más bien crearlos, y nada serían sin la firma de quienes los crean. (Deleuze, 2001, p. 11)

Nos preguntamos entonces, cuánto hay de razón en el proceso de producción estética, cuanto de lógica sistemática, de construcción metódica y cuanto de iluminación, intuición e inspiración poética en la producción de las teorías científicas, habida cuenta que, como señala Deleuze, el concepto es una creación. Pero insistimos, no en el sentido de un barniz, de un complemento que viene a decorar la producción, sino como un rasgo constitutivo y condición de posibilidad de las producciones estéticas y científicas.

Nuestra tradición ha acuñado el concepto de poiesis vinculado a las artes. ¿No podremos entender que también es posible hablar de poiesis científica como aquella fuerza creativa que proviene de la imaginación? El concepto mismo de poiesis no es solamente el de creación, sino el de transformación. Pero, la tradición neopositivista, que todavía impera con mucha fuerza, nos persigue con la idea que la tarea de la ciencia es producir conocimiento, no transformar la realidad y menos ser partícipe de la subjetiva creación. La pretendida neutralidad de la ciencia solo es una astucia para imponer en ese campo el pensamiento único. La lógica subversiva del arte es un frente que el neopositivismo no puede ni quiere abrir, pues debe dedicar todas sus energías a contener las mismas fuerzas subversivas que laten en la ciencia, preservar el dominio para asegurar la conquista del campo, mantener a raya a la voluntad de poder ser de los disidentes. 
Sólo para aquellos que creen que el conocimiento científico es mera explicación objetiva, la ciencia carece del impulso transformador de la realidad y abogan por su pureza -sea básica o aplicada- y dejan la sucia y conflictiva tarea de transformación para la tecnología, eso sí, una tecnología especular del concepto de técnica como dominio. El prejuicio que nos acompaña desde el tiempo de la vieja herencia platónica es que la episteme es razón, conocimiento y verdad y el arte es irracionalidad emoción y en un sentido más compasivo ilusión -cuando no se lo concibe lisa y llanamente como engaño, Platón sic-.

Volviendo al concepto de poiesis, señala Castoriadis que se encuentra en el centro de la creación que desborda los ámbitos del arte y trasciende a la creación histórica y social. Compartimos la idea de este autor que la creación estética no es la mera producción de objetos bellos o sublimes, para usar las categorías de Kant, sino la creación del mundo humano tanto social como individual. Se trata de una acción transformadora que es capaz de generar la dialéctica que religan tiempo y materia, individuo y sociedad. Para Heidegger la poiesis remite al alumbramiento, entendido a éste también en sentido transformador, lo que es una cosa y se convierte en otra. Steiner, en su obra Presencia reales, eleva el acto creativo a niveles teológicos cuando afirma que la existencia del arte mismo significa una apuesta en favor de la trascendencia, en favor de Dios. Bien que pueda pesar a agnósticos y ateos no hay nada que pueda ser pensado como absolutamente trascendente a excepción de Dios, la única idea que remite a lo eterno, imperecedero, perfecto y absoluto es esta. No estamos hablando de su existencia o inexistencia, sino de un tipo de atributos que no pueden ser atribuidos a entidad alguna que no sea Dios, que no sea el Ser en ese pleno sentido ontológico. No hay absolutamente nada en el mundo humano que pueda ser portador de ese tipo de trascendencia, aunque muchos aspiren a ella.

El tiempo inexorable ha de generar cambios en el universo, en el cual, lo humano no será posible, los castillos de naipes de la vanidad humana serán borrados, nada quedará en breve de todo lo que valoramos y el poder escapar de ello se convierte en el oscuro objeto del deseo. Frente a la evidencia de nuestra de fragilidad, inmanencia y finitud surgen la angustia y el temor. El afán de trascendencia divina es la obsesión que ha impulsa el espíritu de Occidente, queremos la inmortalidad a través de Dios, a través del arte, a través de la causa o de la memoria, sin comprender que, como señala Jean Baudrillard en La Ilusión Vital:

Al contrario de lo que pudiera parecer obvio y "natural", las primeras criaturas de la naturaleza eran inmortales. Sólo por lograr la capacidad de morir, a fuerza de una lucha constante, nos hemos convertido en los seres vivos que somos hoy. Ciegamente sońamos en vencer la muerte a través de la inmortalidad, cuando la inmortalidad es siempre el más terrible de los posibles destinos. (Baudrillard, 2002, p.5)

Mientras la ciencia, el arte y la moral sigan a su manera pretendiendo alcanzar la trascendencia, entendida ésta como inmortalidad, como eternidad, ya en el cielo de los espíritus, de los cuerpos resurrectos, del conocimiento verdadero, de la memoria futura, del mármol y del bronce, viviremos en una alucinación pernicio- 
sa y enajenante, sin comprender que la única dicha a la que podemos aspirar es a la de la inmanencia, la que cae en la cuenta que cada segundo es un momento único y que en ello radica su valor, que la posibilidad de eternización del goce conduciría a la tragedia del fijismo muerto. Que el leve roce, que se mide en décimas de segundos, de la mano amada en nuestro rostro, ese goce al que llamamos caricia, lo es por su fugacidad, y su eternización sólo podría producir como señala Baudrillard, el más terrible de los destinos. ¿En qué momento de la historia se pervirtió nuestro anhelo?

La ciencia moderna tiene oscuros antecedentes ocultos y negados, porque hoy se avergonzaría de ellos, aunque son constitutivos de lo sanhelos que siempre la han impulsado; entre ellos la alquimia, la búsqueda del elixir de juvencia y la piedra filosofal que tenían como propósito convertir los metales innobles en oro y hallar la pócima que nos mantenga jóvenes por la eternidad. Estas aspiraciones de la ciencia no han desaparecido y permanecen veladas en los afanes de prolongar la vida lo más posible, en encontrar el gen del envejecimiento, en dominar a la naturaleza para que nos provea de todo lo que necesitamos.

$\mathrm{El}$ arte parece no diferir en sus anhelos de eternidad. Los artistas son como niños que se entretienen con piedras, barro, pinturas, cartones, golpeando y soplando toda clase de objetos, y quieren, en tamañas nimiedades "emular a Dios", al atributo que sólo él podría poseer, es decir, el de creadores. Crear de la nada, he allí una verdadera creación. Pero las actividades de los artistas no más -ni menos- que juegos maravillosos en los que nos regocijamos, entre-tenemos nuestras vidas, las significamos; nos comunicamos con los otros y engendramos de ese modo un mundo que queremos a imagen y semejanza de nuestros deseos. A través de esas prácticas humanizamos el mundo, nos humanizamos y humanizamos el misterio. Esa es su más alta trascendencia, la que no nos transporta al trasmundo, ni señala lo inefable, sino que apenas produce el milagro de la creación del mundo humano.

Para los intentos hegemónicos del poder, que divide para reinar; que se apropia de los saberes, de las creaciones, de los vínculos, y los reduce impúdicamente en mercancías desechables y con fecha próxima de vencimiento, el cruce en el que se pueden encontrar la ciencia y el arte, junto con la técnica, el juego, el placer y el goce, es un cruce peligroso, ya que puede ampliar nuestras miras hacia un horizonte des-enajenado, signado no por "la verdad", sino por la "significación", no por "el conocimiento" sino por "la sapiencia", no por "la moral" que es el deber ser, sino por la "ética" que es el encuentro con el otro en el respeto por la diferencia.

Hay una idea que conmovedoramente nos propone Steiner, pero que luego traiciona imbuido de la mezquindad del afán de eternidad. No parecen escritos por el mismo autor estos dos textos:

Este estudio se propone sostener que la apuesta a favor del significado del significado, a favor del potencial de percepción y respuesta, cuando una vos humana se dirige a otra, cuando nos enfrentamos al texto, la obra de arte o la pieza musical, es decir, cuando encontramos al otro en su condición de libertad, es una apuesta a favor de la trascendencia. (Steiner, 1990, p. 14) 
Es conmovedora esta frase de Steiner, ella da cuenta del auténtico acto de trascendencia que le es posible alcanzar al hombre, ni más ni menos que salir de su encierro solitario, encontrarse con el otro, lograr la comunicación; habida cuenta que la condición para alcanzar todo esto es la libertad. Lamentablemente luego abandona Steiner esta premisa y reafirma con la tradición, que:

El texto, la pintura, la composición son apuestas por la durabilidad, Encarnan el dur désier de durer, (el duro deseo de durar). (Steiner, 1990, p. 41)

Es cierto, la vida quiere durar, ese es su afán de preservación, pero parte de su aprendizaje es entenderse y armonizarse con la muerte. La vida que no sabe morir es una traición a la vida. No se trata de hacer culto de la muerte, sino de celebrar la vida, y la celebración tiene sentido sólo cuando la certeza de la muerte la alcanza, una vida eterna no merecería ser celebrada, porque no celebramos lo ordinario, sino lo extraordinario. El valor del genio artístico no radica meramente en su virtuosismo para la ejecución, sino en alumbrar lo extraordinario mediante la creación. Pero, ¿qué es lo extraordinario? Ya sea mediante ecuaciones matemáticas, contrastaciones empíricas, música, pintura, literatura, cocina, lo extraordinario es lo que se revela a través del significado del significado. En este sentido la creación es una tarea sin fin, porque lo extraordinario deja de serlo, cae en lo habitual, en la costumbre, en lo ordinario. La durabilidad de la obra de arte en el tiempo no es debido a algún misterio oculto propio de la obra, a una facultad sobrenatural para trascender, es a consecuencia de la capacidad resignificadora que puede provocar. En parte se encuentra en la obra, es la que la recrea y que está en parte en la obra pero también en la sociedad. La vida de la obra de arte no radica en su creación, sino en su recreación constante, abierta a su suerte histórica y su realización colectiva. Porque nosotros somos lo extraordinario, en tanto no somos lo dado, sino lo que se recrea constantemente. Por ello es que la reconciliación entre el arte y la vida se ha mostrado como algo vital para el arte; en tanto la reconciliación entre la ciencia y la vida para la ciencia no ha representado mayor necesidad. Mientras que la ciencia, en gesto enajenante, se sustrae del mundo, de la vida cotidiana, creando su propio y frio mundo de certeza y abstracción, el arte genuino requiere de las tibiezas de la vida, de las ambigüedades del placer y del dolor, del anhelo por recuperar sus lazos con la vida, que el arte enajenado perdió en los mercados de la modernidad.

En Modenidad un proyecto incompleto Habermas (1998) nos habla del fracaso de las vanguardias estéticas, el cual radica en haber profundizado la separación entre arte y vida, entre arte y sociedad proponiéndose por el contrario su reconciliación. En su análisis, Habermas revela con crudeza la paradoja estética de la reconciliación desde una de las esferas, en este caso, la del arte. Pero señala que no hay intento alguno de la ciencia por conciliar y reconciliarse con el arte y la moral. Sencillamente porque tal problema no se encuentra planteado para la ciencia. Es más, para las corrientes dominantes, tal proyecto solo puede ser concebido como especulaciones filosóficas, como ficciones de quienes no llegan a comprender cuál es la verdadera tarea de la ciencia. La sola idea de relacionar ciencia y arte les pare- 
ce delirante, propias de la pseudociencias que han contaminado el mundo académico y que pretenden retornar al pensamiento mágico. Por otra parte, en esos ámbitos "delirantes" estos problemas se presentan en el orden de la reflexión, de la crítica, de los debates con el neopositivismo y con el cientificismo, esto no es poco, pero en nuestro medio son escasas las voces que aportan reflexiones verdaderamente innovadoras y buena parte de los que procuran un "dialogo" entre ciencia y arte no lo hacen pensando en su integración, sino en la ampliación de los recursos de su propio campo.

Usar computadoras o recursos tecnológicos para una instalación, o ilustrar con pinturas o esculturas un "paper" no es reconciliar el arte y la ciencia, es sólo dar impulso a la industria cultural. Pero hay un ejemplo de una actividad que a lo largo de los siglos no ha perdido el nexo creativo entre ciencia, arte, naturaleza, técnica y moral, aunque por supuesto sin dejar de estar expuesta a valores epocales que la han proyectado en múltiples corrientes. Nos referimos a la arquitectura. En la arquitectura moderna tendencias cientificistas, racionalistas, funcionalistas como el caso de la Bauhaus han convivido con otras que han tenido la intención de una verdadera reconciliación, reunificación de las esferas escindidas, antes que servirse parasitariamente de las otras esferas. Nos parece que un ejemplo notable es la obra de Antonio Gaudi.

Llevar al terreno propio al enemigo es la primera estrategia del combate. En la lucha por la conquista de los campos, lo importante, -siguiendo una expresión periodística- es fijar la agenda. No se trata simplemente de sumar temas, ni de aceptar lo distinto como una forma de repreguntarse por lo propio, lo primero es establecer el orden del día planteando una forma discursiva que tenga por intención romper con los discursos hegemónicos de los que dominan.

En los cada vez más extendidos formularios informáticos para solicitud de becas, concursos, investigaciones, etc. de nuestras universidades y centros e institutos de investigación, los campos del formulario vienen acompañados de opciones de las que sólo se pueden elegir aquellas que forman parte de la lógica cientificista. En algunos casos el riguroso listado de opciones tiene la particular deferencia de poner "otros". Esos otros que no se encuentran reconocidos por la lógica institucional, que no son identificados con las temáticas propias de los evaluadores, esos otros que aunque tienen nombre propio no se los nombra y que como verdaderos $\mathrm{NN}$ caen en lo genérico marginal, los otros, los no importantes, los no relevantes, el espacio para lo raro, los que no son nosotros. Desde esas perspectivas la epistemología se presenta como lógica de la investigación, como metodología de la ciencia o como filosofía de la ciencia, pero no como filosofía en sentido amplio, sino como la reflexión sobre los límites de la ciencia que se obstina en poner una gran distancia con lo que para ella son excentricidades de una actividad inconexa con sus prácticas y sus propósitos.

La voluntad de poder ser con los otros, que quiere expresar un ser integral, no es algo nuevo. Apenas se consolida la separación de las esferas de la ciencia el arte y la moral, surgen voces que denuncian la tragedia que se está consumando. Una de esas voces, quizás atenuada por el tiempo es la de J.C.F. Schiller. En medio de una creciente disputa entre los dos más importantes movimientos de la modernidad, la ilustración y el romanticismo, Schiller se presenta con las Cartas para la educación 
estética del hombre, como alguien que quiere recuperar la integridad de las esferas, que quiere reconciliar lo que la ilustración y el romanticismo están separando aceleradamente. Y son las condiciones existenciales de Schiller las que le revelan la emergente esquizofrenia. Su profesión de médico, su condición de filósofo, sus realizaciones como poeta y dramaturgo lo hacen transitar tanto por el corazón de esas disciplinas como por las intersecciones, los quiebres y las rupturas. Alto fue el precio que pagó siendo despreciado por románticos e ilustrados. Pero dejemos que sea el mismo Schiller quien nos hable:

La misma civilización fue la que infirió esa herida a la humanidad moderna. Tan pronto como, de un lado, la experiencia ampliada y el pensamiento determinador hicieron necesaria una división más rigurosa de las ciencias, y, de otro, el complicado mecanismo de los Estados una clasificación más estricta de las clases sociales y de los negocios, rompió también el lazo íntimo de la naturaleza, y una pugna perniciosa desunió sus fuerzas armónicas. El entendimiento intuitivo y el especulativo se encerraron en sus campos hostiles, cuyos límites empezaron a vigilar con desconfianza y recelos; el hombre, al restringir su actividad a una sola esfera, se ha dado a sí mismo un amo despótico que suele concluir por oprimir las demás facultades del espíritu. Mientras una imaginación lujuriante agosta los laboriosos brotes del entendimiento, el espíritu de abstracción apaga el fuego que hubiera debido caldear el corazón y encender la fantasía. (Schiller, 1981, pp.43, 44)

Poco nos queda por agregar a esa síntesis maravillosa, extraordinaria, con que Schiller significa, no solamente el espíritu de la modernidad, sino que además señala las necesarias tareas del futuro. Son estas palabras las que resuenan en Adorno, Benjamin, Marcuse, Habermas. Son estas ideas las que ponen la cuestión en el centro mismo de los desafíos que tanto él, como Kant, pensaban para más de un siglo y que, pasados dos siglos largos, todavía siguen pendientes.

\section{BIBLIOGRAFIA}

—Adorno, Theodor: Dialéctica del Iluminismo, Editorial Sur, Buenos Aires, 1970

—Boudillard, Jean: La Ilusión Vital, Editorial Siglo XXI, Buenos Aires, 2002

-Carpentier, Alejo: El Reino de este Mundo, Compañía general de ediciones S. A, México, 1973

—Deleuze, Gilles: ¿Qué es la filosofia? Editorial Anagrama, Barcelona, 2001.

—Einstein, Albert: Mi credo humanista, Copyright www.elaleph.com2000

-Epicuro: Opere, Einaudi Editori, Torino 1973.

- Habermas, Jürguen: Revista Punto de Vista No 21 Buenos Aires agosto de 1998.

- Horkheimer, Max: Crítica a la razón Instrumental, Editorial Sur, Buenos Aires, 1973.

—Marcuse, Herbert: Eros y civilización, Seix Barral, Barcelona, 1969.

-Marinetti, Filipo: Manifiesto futurista, Editorial Quadrata, Buenos Aires, 2007. 
56 / Perspectivas Metodológicas

—Platón: La República, Alianza Editorial, Madrid 2008.

-Schiller, JCF: Cartas sobre la educación estética del hombre, Editorial Aguilar, Buenos Aires, 1981.

—Steiner, Georg.: Presencias reales, Editorial destino, Barcelona, 1989.

—Weber, Max.:: "La ciencia como vocación", El Trabajo Intelectual como Profesión, (Trad. A. K. Meszaros), Barcelona, Bruguera, 1983, pp. 10 a 59, 1918. 